\title{
AD HOC approach of cost management during the time of COVIDization of the economy
}

\author{
Radko Radev ${ }^{1 *}$, and Alexander Naidenov ${ }^{1}$ \\ ${ }^{1}$ The University of National and World Economy, Sofia, Bulgaria
}

\begin{abstract}
This article aims to present the ad hoc approach of cost management taken by the companies under the conditions formed due to the COVIDIzation of the economy. Considering the uniqueness of the situation caused by COVID-19, the term COVIDization of the economy is interpreted. In general, it means complex changes in the PESTEL environment, conditioned by the global health crisis. For the majority of companies, these changes had an adverse effect. For others, it was neutral or favorable. The onset of the first wave of COVID-19 found most companies unprepared, with planned revenue, cost, and profit levels. In the face of a sharp change in revenue levels, firms had to respond ad hoc to meet these challenges. The publication brings out the ad hoc approach of cost management as a theoretical statement. It presents the effects on the revenues of the first wave of COVIDization and the companies' ad hoc actions about their costs. Two studies conducted by the SRC Innovation and Competitiveness (U2B) were used in the current publication. They were conducted during the locked-down in 2020 and April-May 2021.
\end{abstract}

\section{Introduction}

During the second quarter of 2020, the companies in the world and Bulgaria faced the initial challenges, conditioned by the influence of COVID -19. As a result of the locked-down imposed by the government, certain sectors of the economy were negatively affected. Many companies recorded a sharp drop in their revenues. In specific sectors, the revenues practically stopped. The abrupt change of revenues led to a deterioration of companies' financial performance. It argued a need to change business plans and the values of the main economic ratios. In these conditions, the ability of companies to make crisis decisions related to costs has manifested itself. The strategies and approaches known in the theory and practice of cost management have to be reconsidered in the context of adverse effects of COVIDIzation of the economy.

The thesis advocated here is that companies should find adequate costs solutions to respond to a force majeure situation during a sharp and unexpected revenues change. Their finding is defined as an ad hoc approach in cost management. It allows informed and argued short-term costs-oriented decisions without losing the long-term perspective for the company's development.

The article aims to bring out as a theoretical statement an ad hoc approach in cost management and to present its specific manifestations during the initial stage of COVIDIzation of the economy. The following set of tasks were completed: first - the meaning of the term COVIDization of the economy is clarified; second - the importance of

* Corresponding author: r.radev@unwe.bg 
an ad hoc approach for overcoming the harmful effects of COVIDization is argued; third the set of the ad hoc actions by which companies overcome the negative effects of the sharp decline in revenues results are presented.

Special attention is paid to cases in which COVIDization effects negatively companies' activities and financial ratios. The initial impact of COVID-19 necessitated taking actions to overcome the adverse effects in the short term, which were reconsidered and adopted as a cost-optimization policy.

\section{Literature review}

\subsection{The role of costing and cost management}

According to the Chartered Institute of Management Accountants, the cost is "the amount of expenditure (actual or notional) incurred on, or attributable to a specified thing or activity." [1] The value-added chain integrates companies' activities, classifying them as primary and secondary (support activities). Through these activities, companies manufacture material products or provide services to satisfy customers' needs for achieving their financial goals. [2] The importance of cost management lies in the understanding that competitive companies manage to meet the needs of their target markets more efficiently than their competitors [3]. Cost management is at the heart of achieving higher efficiency and hence to financial goals in the short and long term. [4]

Cost management has permanent importance for the efficiency of business operators. It occurs at every stage of the life cycle of product and enterprise development [5]. The cost management importance is also determined in the context of external environment factors [6], business strategy [7], investment management [8], planning and budgeting process [9], decision-making process [10], controlling and cost reduction [11].

The importance of cost management even increases during the time of crisis, especially if the crisis occurs suddenly and has serious adverse consequences. [12-14] Such a type of crisis was driven by the emergence of the first wave of COVID-19. The short-term effects, predominantly unfavorable and long-termed consequences, caused by this wave argued the perception of the term COVIDization of the economy. The most damaging consequence was a sharp decrease in revenue. In certain economic activities, they have practically stopped. The companies negatively influenced had to find quick ad hoc solutions to address problems without losing their strategic focus [13-14].

\subsection{Ad hoc approach of cost management}

Applying the ad hoc approach of cost management requires knowledge of cost classifications including: 1) by time (historical, pre-determined); 2) by nature or elements (material, labor and overhead); 3 ) by a degree of traceability to the product (direct, indirect); 4) association with the product (product, period); 5) by changes in activity or volume (fixed, variable, semivariable); 6) by function (manufacturing, administrative, selling, research and development, pre-production); 7) relationship with accounting period (capital, revenue); 8) controllability (controllable, non-controllable); 9) cost for analytical and decision-making purposes (opportunity, sunk, differential, joint, common, imputed, out-of-pocket, marginal, uniform, replacement); 10) others (conversion, traceable, normal, avoidable, unavoidable, total). [1516]

The ad hoc approach of cost management has to be applied as an essential part of management accounting. Its perception in this way is a prerequisite for taking appropriate managerial decisions in the context of a force majeure situation [12-14]. Management 
accounting as an extension of management aspects of cost accounting provides the information for business operation management. It overcomes the limitations of financial accounting, which referred only to the records of business transactions [15-16]. Management accounting plays an irreplaceable role in the optimum utilization of existing resources. Their inherent techniques help to solve specific problems and serve as guidelines for decisionmaking.

There are many costing methods used in cost management that help achieve higher company efficiency: job-centered - they include job, contract, batch, and terminal costing; process and product-oriented: operation costing, process costing, unit or single or output or single-output costing, multiple or composite costing, departmental costing; popular qualification of costing tools includes historical (or conventional), standard, marginal, uniform, direct, absorption, and active-based costing [15-16]. Cost management is not simply the process of planning a company's budget and controlling the spending of money according to the budget. It also includes anticipating operating costs and keep them under control, offering products at reasonable prices [5-14]. Cost management in management accounting provides managers at different levels with relevant information for planning, decisionmaking, and control [9-11]. It is at the heart of achieving efficient management and making sound management decisions [17].

There are some general well-established financial management approaches used in management accounting: 1) financial planning and budgeting; 2) financial analysis; 3) decision-making process; 4) controlling; 5) statistical techniques; 6) reporting [15-16]. They possess a methodological toolkit and mutuality. These approaches are an integral part of strategic and operational management. Likewise, they are used in cost management to achieve higher efficiency and balance short-term goals and companies' strategical development [15-16]. The role of cost management is more pronounced during crises that occur suddenly without being expected [12-14]. They are particularly pronounced in the presence of a sharp drop in revenues when timely solutions are required. In such cases, competence in cost management is needed to find reasoned solutions. Finding such solutions is defined as Ad hoc approach in cost management. This approach should be perceived as leading in the initial stage of COVIDization of the economy [13-14]. The Ad hoc approach involves using formal methodology, methods, and tools inherent in management accounting. It solves short-term problems driven by the sharp decline in revenue (and not only) while staying focused on the company's long-term development [13-14].

The capacity of the Ad hoc approach of cost management increases when a business information system is available. It increases, even more when big data management exists in the following general strands: business process data, product or service data, customer data. It leads to fast and argued decisions considering many different scenarios; greater efficiency and productivity lowering costs and improving profitability [18].

\subsection{The role of Ad hoc approach according to the strategic position}

In the short term, the ad hoc approach of cost management may aim for the company to survive or improve its strategic position. The aim will depend on the strategic position and the influence of external conditions. Thus, the ad hoc approach is understood to find specific cost solutions to resolve particular problems. This view does not deny the need to address costs in the long term (strategic development).

When the environmental conditions require solving specific problems, a more active approach to cost management is needed. It requires managers to find an adequate approach (strategy) to overcome unfavorable circumstances without losing the long-term strategic focus. Among the necessary basic conditions for completing this requirement is the knowledge about costs classification, their behavior, and the importance they have for 
companies' sustainable development. Their management requires the possession of competencies about methodological characteristics of management accounting.

\section{Methodology}

The article uses results from two surveys carried out by SRC Innovation and Competitiveness. These studies focus on the COVIDization of the economy, its impact on business, and the measures taken by companies. The targeted audiences were companies' managers and owners. The first survey aimed to research the effects of the locked down on the companies' performance and identify activities undertaken for solving problems encountered, including costs-oriented decisions. It covered 176 companies from different sectors of the economy. The second survey covers the third wave of COVID-19 and included 243 companies. It examined the effect of the measures taken by the company during 2020 . Both studies also explore questions that identify what strategic changes were envisaged in response to short-term impact and long-term consequences of COVIDization.

Both studies include three main sections. The first section aims to collect information on the company's main characteristics - income, the value of assets, number of employees, information on the financial position and financial condition - profitability of income, solvency, liquidity. The second section examines the impact of COVIDization, including the influence on revenues and profits. The third section identifies the actions that help companies overcome adverse effects caused by the first wave of COVIDization of the economy. This section collects information about costs ad hoc decisions, including wage costs, marketing and sales, administrative costs, training costs, and social benefits. The fourth section allows gathering information about the companies' intentions for adaptation and strategic change that the companies intend to undertake in the middle and long term. The scope of the study does not address issues concerning methodological characteristics of management accounting and its place for efficient management. The data collected helps to identify only ad hoc cost-oriented decisions taken by the companies.

\section{Results}

Managers' competencies and their understanding of the central role of cost management in strategic and operational decisions are crucial for taking the right set of ad hoc costs measures. The survey focused on the classification characteristics of the costs, their behavior and importance for companies' profitability. The results presented here detect the set of ad hoc cost-oriented actions taken by the companies in response to the negative impact of COVIDization on the economy during 2020.

\subsection{Ad hoc cost-oriented action taken by the companies during the first wave of COVIDization}

There are four degrees to determine the negative impact of COVIDization of the economy: first degree is observed when the effect is extremely unfavorable due to the locked-down companies from specific sectors temporarily suspends their activities; second degree is defined as bellow extremely unfavorable - there is a decrease in revenue of more than $50 \%$; third degree - highly unfavorable, when the drop in revenue is between 20 and $50 \%$; fourth degree -the impact is unfavorable but surmountable - when the decline in revenues is up to $20 \%$. The total share of companies where the influence is unfavorable in one of the four degrees amounts to $74 \%$ : the ultimate degree of adverse impact is formed at $9 \% ; 23 \%$ of the companies involved in the survey register a drop more than $50 \%$; in $19 \%$ of companies 
the decline is $20-30 \%$ - the situation is defined as highly unfavorable, and in $24 \%$ as unfavorable but surmountable. Companies where the influence is a neutral amount to $17 \%$. In the rest of the companies, the influence is defined as favorable. (Fig. 1)

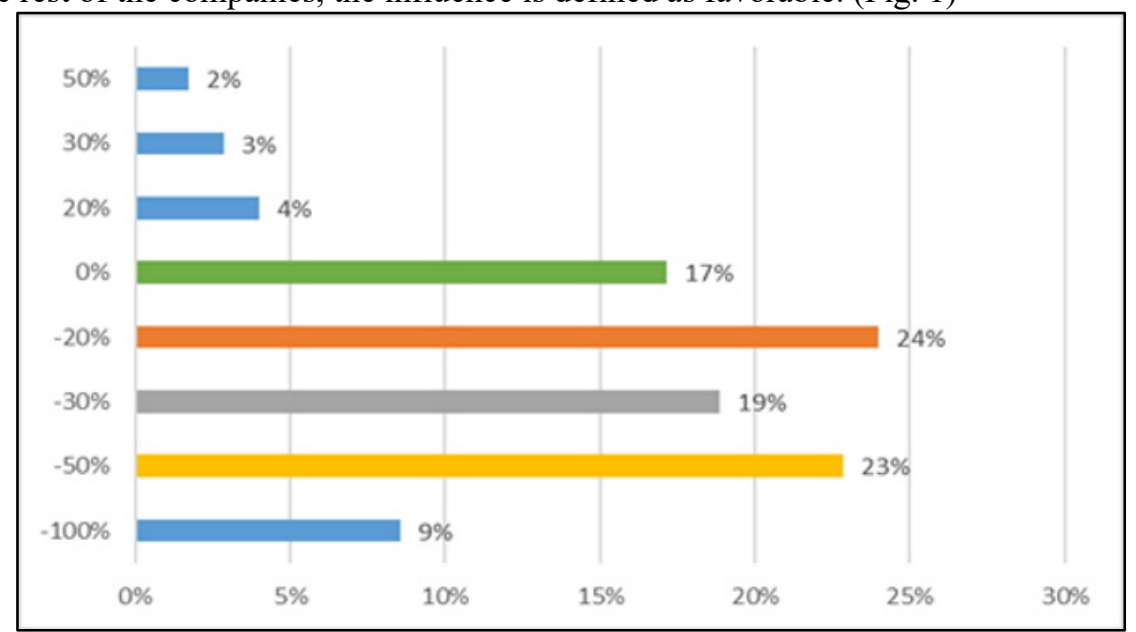

Fig. 1. Decrease/growth of the revenues in March-April 2020 compared to the same period of 2019

Since the vast majority of companies were not prepared for the harmful effects of COVIdization on the economy, they had to take ad hoc cost-related actions. Thus, the circumstances forced the companies to apply an ad hoc approach of cost management consciously or not. At the heart of the actions taken were the strategic position and financial situation in which the first wave of COVID-19 found the companies. (Fig. 2)

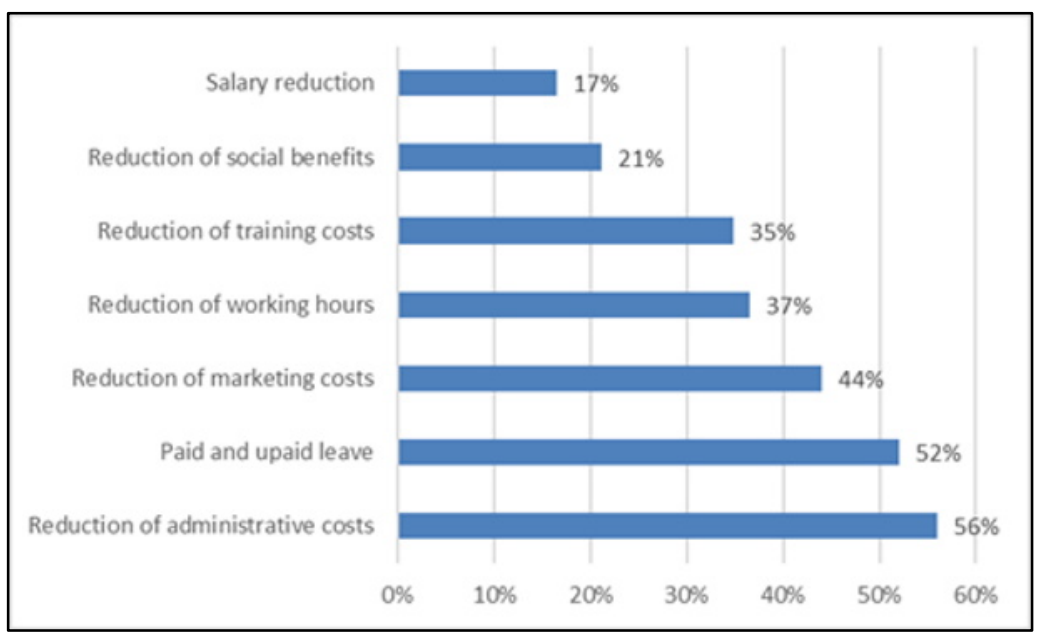

Fig. 2. Ad hoc cost-oriented action for overcoming adverse effects caused by the first wave of COVID-19 and locked-down

The main focus of ad hoc action falls on administrative costs as the main ingredient of indirect and fixed costs. Almost $56 \%$ of participants in the study took their reduction. The next meaningful measure taken by $52 \%$ of all companies in the sample refers to employees' leaves and dismissions. The pessimistic expectations drove sales and marketing cost reduction. A reduction in the working time is carried out by $37 \%$ of companies. Training costs cut is a preferred issue for $35 \%$ of firms. $21 \%$ take away social benefits given before locked down. The decrease in the salaries is considered as an appropriate measure for $17 \%$ 
of companies. When asked about the actions they intend to take in the middle and long term, $68 \%$ of companies pointed that they are going to turn cost optimization into their priority.

\subsection{Assessment of Ad hoc cost-oriented action taken by companies during the COVIDization of the economy in 2020}

\subsubsection{Change in revenues in 2020 compared to 2019}

In most companies, there is a decrease in revenues in 2020 compared to those achieved in 2019. As a result, they got away from their preliminary financial plans. The lagging of revenues during the lock-down that companies registered, compared to 2019, was highly unfavorable and portended deteriorating their profitability. The actions taken by companies after the locked-down led to greater or lesser compensation of the revenue gap. (Fig. 3)

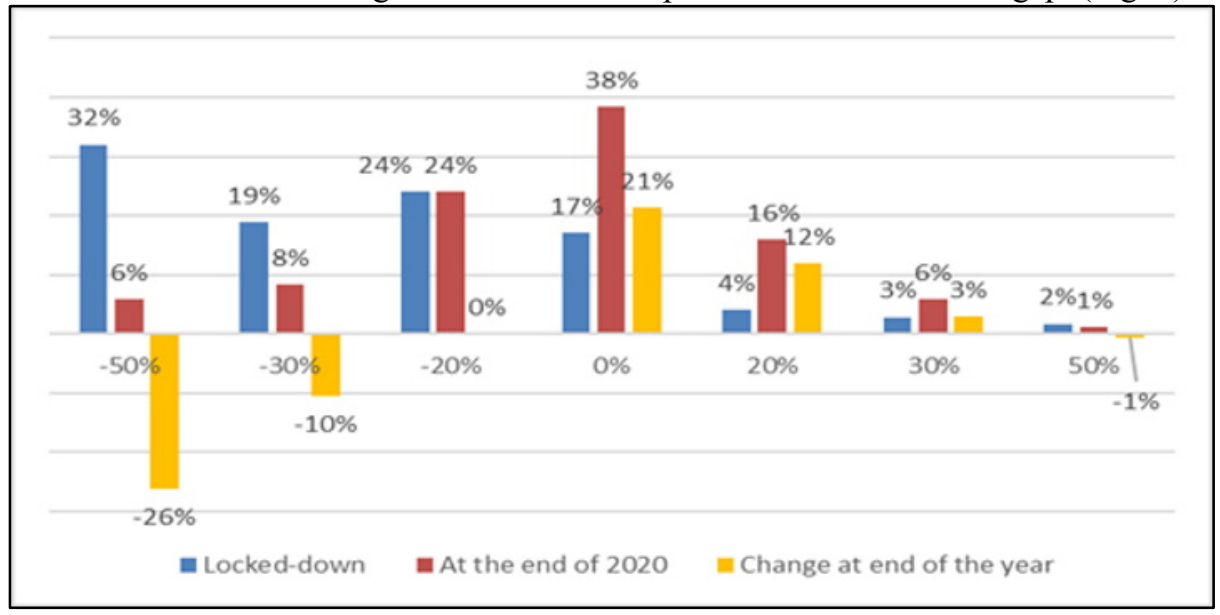

Fig. 3. Share of companies according to the decline/increase in revenues in 2020 compared to 2019

The rate of adverse change in revenue during lock-down compared to March-April 2019 was highly damaging for more than $70 \%$ of the companies. Due to the actions taken by the companies after locked-down cancelation, more of them managed to improve their results. From $32 \%$ e share (marked in blue), companies with revenues drop bigger than fifty percent fell to $6 \%$ (marked in red). This movement is a positive change with twenty-six percentage points (marked in orange). The relative weight of companies with a decrease in revenues higher than $30 \%$ decreases by ten percentage points (From 19\% to $8 \%$ ). The group of companies with a decline of $20 \%$ and more stayed $24 \%$ at the end of the year. The number of firms which revenues remained unchanged thrives, reaching a higher relative share (from 17 up to $38 \%$ ). There is s significant positive change in companies with revenue growth of up to $20 \%$. The large relative shares of companies with a decrease of revenues $(40 \%)$ and companies achieving the same level (38\%) determine the importance of cost management.

\subsubsection{Post factum assessment of Ad hoc cost-oriented actions}

The adverse effects of the first COVID-19 wave on revenues force affected companies to find solutions to face the challenges. Taking ad hoc cost-oriented decisions played a crucial role in surviving locked-down through the whole of 2020. The ad hoc survival actions have been transformed into cost optimization policies in the medium and long term. (Fig. 4) 


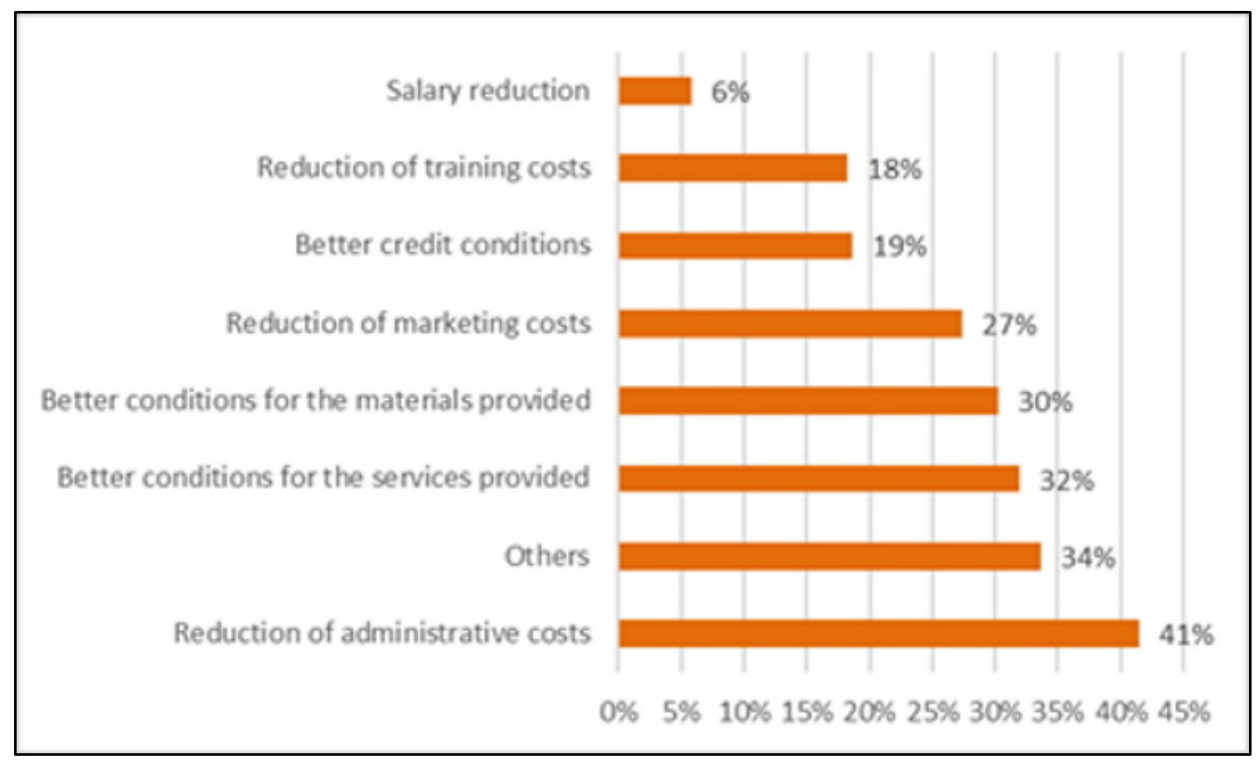

Fig. 4. Evaluation of Ad hoc actions related to costs

As a result of the survey, conducted in April-May 2021, a post factum assessment of the ad hoc cost decisions was carried out. It identified those decisions that played the most crucial role in coping with the harmful effects of COVIDIization during 2020. The figure shows that to reducing administrative costs $(41 \%)$ was paid the greatest attention. Reducing the expenses for external services (34\%) and raw materials (32\%) are the next important decisions. $27 \%$ of the companies took the reductions of their marketing and sales costs.

The analysis of the survey results shows that throughout 2020 companies focused on optimizing the different types of operating costs, including direct and indirect, fixed and variable ones. That confirmed the intention of $68 \%$ of companies stated in the survey during the locked-down to undertake cost optimization in the short and middle term. Thus, the ad hoc approach to cost management, used in the second quarter of 2020, evolved into a targeted policy that continued during post-locked-down months, the second COVID-19 wave, and after.

\subsubsection{Influence ad hoc approach of cost management on profit}

The sharp revenues decrease, influenced by COVID-19 first wave, forced companies to take emergency cost-oriented decisions. Consciously or not, these decisions came about as a result of formal or not formal decisions. In companies where the ad-hoc approach is conscious and formal, the decisions made are the result of a purposeful process of cost management. The quick revenues decrease, influenced by COVID-19 first wave, forced companies to take emergency cost-oriented decisions. Conscious or not, these decisions came as a result of formal or not formal decisions. In companies where the ad-hoc approach is conscious and formal, the decisions taken are the result of a targeted cost management process. In the rest ones, it is applied intuitively and on the basis of the management experience. As a result of the cost decisions taken through the ad hoc cost decision approach, significant compensation of the financial result was achieved. Evidence of this claim is the structure of the companies according to the change of revenues and profit achieved in 2020 compared to 2019. The two structures examined below confirm the importance of the ad hoc approach of cost management (cost-decisions) in the context of COVIDization of the economy. (Fig.5) 


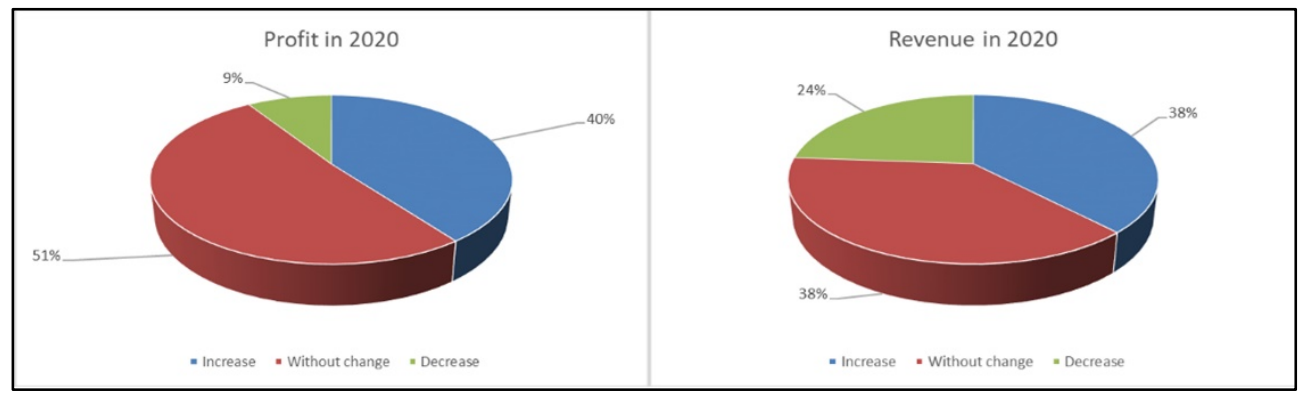

Fig. 5 The structure of the firms according to the change in revenues and profit in 2020 compared to 2019

Revenue growth is recorded in $38 \%$ of companies, and profit growth is at $40 \%$. The revenue slumped by $38 \%$ and stay unchanged in $24 \%$ of firms. The companies with a profit decline are $9 \%$, and those that keep the profit level amount to $51 \%$. The positive effect of the ad hoc cost-oriented decisions during the locked-down and policy of cost optimization taken in the post-locked-down months prepared the company to meet the challenges of the second COVID-19 wave and the third one that followed. As a result of companies' purposeful efforts, there was a gap between the share of these companies, which register profit decline $(9 \%)$, and those with revenue slump (24\%). This positive fifteen-percentage-points-gap is indisputable proof of the importance of ad hoc cost-oriented decisions. Thanks to making these decisions, more companies managed to stay profitable even with revenue decrease. The gap between the revenue planed and the revenue achieved in the subperiods during 2020 also necessitated a revision of costs. Thus, the magnitude of positive effects to be even bigger if we consider the companies which managed to keep the level of the revenue, they had in 2019.

\section{Conclusion}

The role of cost management for the companies' efficient management is indisputable and irreplaceable. It even has been increasing since the first COVID-19 wave and, locked down followed. During COVIDization of the economy, an active ad hoc approach in cost management manifested its role. This approach includes the inherent accounting principles, methods, and tools. The Ad hoc approach helps to find solutions quickly without losing the long-term strategic perspective. It is this approach that was taken as leading in cost management. Proof of this is that during the three subperiods during 2020 (locked-down, post-locked-down months, and the second COVID-19 wave), companies managed to survive and offset the decline in revenue through the ad hoc cost-oriented decisions. Their positive impact on companies' was presented. The survey focused only on the identification of costoriented decisions. In the future, Ad hoc approach study of cost management should be enriched with questions related to the principles, approaches, and tools of management accounting. Due to the scope of the studies carried out, these aspects were not addressed in this publication.

\section{References}

1. J. K. Mitra, Advanced Cost Accounting, (New Age International, 8, 2009)

2. M. Porter, Competitive Advantage: Creating and sustaining superior performance, (New York: Free Press, 32-52, 1985) 
3. P. Kotler, K. 1. Keller, Marketing Management, 12th Ed., (Pearson Education, 21-30, 2006)

4. A. Wiltshire, How to Strategize Short-Term and Long-Term Cost Optimization, Shibumi, (2020), [Online], https://shibumi.com/blog/how-to-strategize-short-term-andlong-term-cost-optimization/, [Accessed: 15 July 2021]

5. J.-H. Park, K.-K. Seo, D. Wallace, K.-I. Lee, CIRP Annals, 51(1), 421-424 (2002)

6. S. Shahzadi, R. Khan, M. Toor, A. ul Haq, AJAR, 3(2), 211-223 (2018)

7. J. K. Shank, J. H. Shank, V. Govindarajan, Sh. Govindarajan, Strategic Cost Management: The New Tool for Competitive Advantage, (Simon and Schuster, 1993)

8. E. Bloch, D. E. Stout, D. F. Stout, S. Smith, P. E. Juras, S. D. Smith, ISE Cost Management: a Strategic Emphasis, 8th Ed., (McGraw-Hill Education, 2018)

9. J. Alexander, Financial Planning \& Analysis and Performance Management, (John Wiley \& Sons, Inc, 2018)

10. S. Takasaki, H. Tamura, M. Nagayama, Corrosion engineering, 36(2), 91-95 (1987)

11. J. Prescottm, The Best Ways for a Financial Manager to Save Money, (Managing Ed., IOMA, 2006)

12. I. I. Mitroff, P. Shrivastava and F. E., Udwadia, (AME) Acad. Manag. Exec., 1(4), 283- 292 (1987)

13. Cost Resilience amid and after COVID-19 Thriving in uncertain times, Deloitte (2020), [Online], https://www2.deloitte.com/content/dam/Deloitte/be/Documents/monitor-deloitte/Costresilience-amid-and-after-covid-19.pdf, [Accessed: 13 June 2021]

14. Getting Fit For Business: Forecasting and Managing Costs, RwC, (2020), [Online], https://www.pwc.com/my/en/assets/publications/2020/pwc-covid-19-getting-fit-forbusiness-forecasting-and-managing-costs.pdf, [Accessed: 13 June 2021]

15. The Institute of Company Secretaries of India, Executive Programme: Cost And Management Accounting, MODULE 1, PAPER 2, (2017), https://www.icsi.edu/media/webmodules/publications/FULL_BOOK PP-CMA-2017JULY 4.pdf, [Accessed: 15 July 2017]

16. C. Drury, Management and Cost Accounting, 10th Ed., (Cengage Learning EMEA, 2018)

17. J. Godey, Six steps to effective cost management, CPA Journal Online (1994), http://archives.cpajournal.com/old/16373966.htm

18. D. L. Rogers, Digital Transformation Playbook: Rethink your Business in digital age, (Columbia University Press, 2016) 